\title{
Powerful Electromagnet for the Use of Oculists
}

\section{A Convenient Form of Apparatus for Extracting Iron and Steel Splinters}

By C. Van Langendonck

THE electromagnet designed for the use of oculists 1 by Dr. Haab, director of the Zurich eye clinic, and sliown in the accompanying photographs, is the most powerful and efficient apparatus of this kind in existence. According to Dr. Haab, the principal requirements of such an instrument are the following:

1. The magnet must be capable of developing very great tractive force.

2. It must be placed horizontally, and its circuit must be made and broken by the operation of a pedal.

3. The working pole must have a form adapted to its peculiar function and its dimensions must bear the proper relation to those of the coil.

The first condition is very important. The smal electromagnets which are commonly used by oculists often fail at the critical moment, owing to their lack of adequate magnetic strength, and thus endanger the success of the operation.

The method of making and breaking the circuit by the foot of the operator possesses great advantages, because it leaves both hands free for the control of the eye and body of the patient, and makes it unnecessary to remove the magnet in order to stop its action. This last point is exceedingly important for, even with the most perfect suspension, it would be impossible to withdraw the heavy electromagnet from the eye quickly enough to prevent the iron filing or other foreign substance from being drawn into a region where its presence is not desired. When the circuit is: opened and closed by a pedal the magnet need not be suspended.

Dr. Haab regards the suspension method not only as impracticable for the heavy magnets which he employs, but as incorrect in principle. His experience proves that it suffices to support the magnet in such a manner that its axis can be turned to any direction in a horizontal plane.

In regard to the form of the working pole, it is obvious that its action will we weakened in proportion to the extent to which it protrudes from the coil. It must not, however, be so short that the coil interferes with the view of the field of operation, as is the case in some of the newer large electromagnets. The magnet is of the bell form. The working pole is a cone of 90 degrees, and this end of the coil is
tapered sufficiently to give the operator a clear view of the field up to the tip of the magnet pole. Four pointed tips accompany each apparatus.

The idle pole is expanded into the form of a bell which covers and protects the greater part of the coil. This construction possesses the additional advantage of restricting the escape of lines of force to one side and diminishing the area of the external magnetic field.

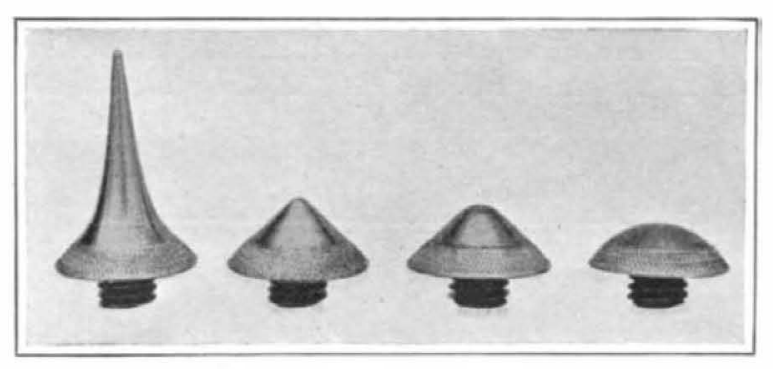

A set of pole points.

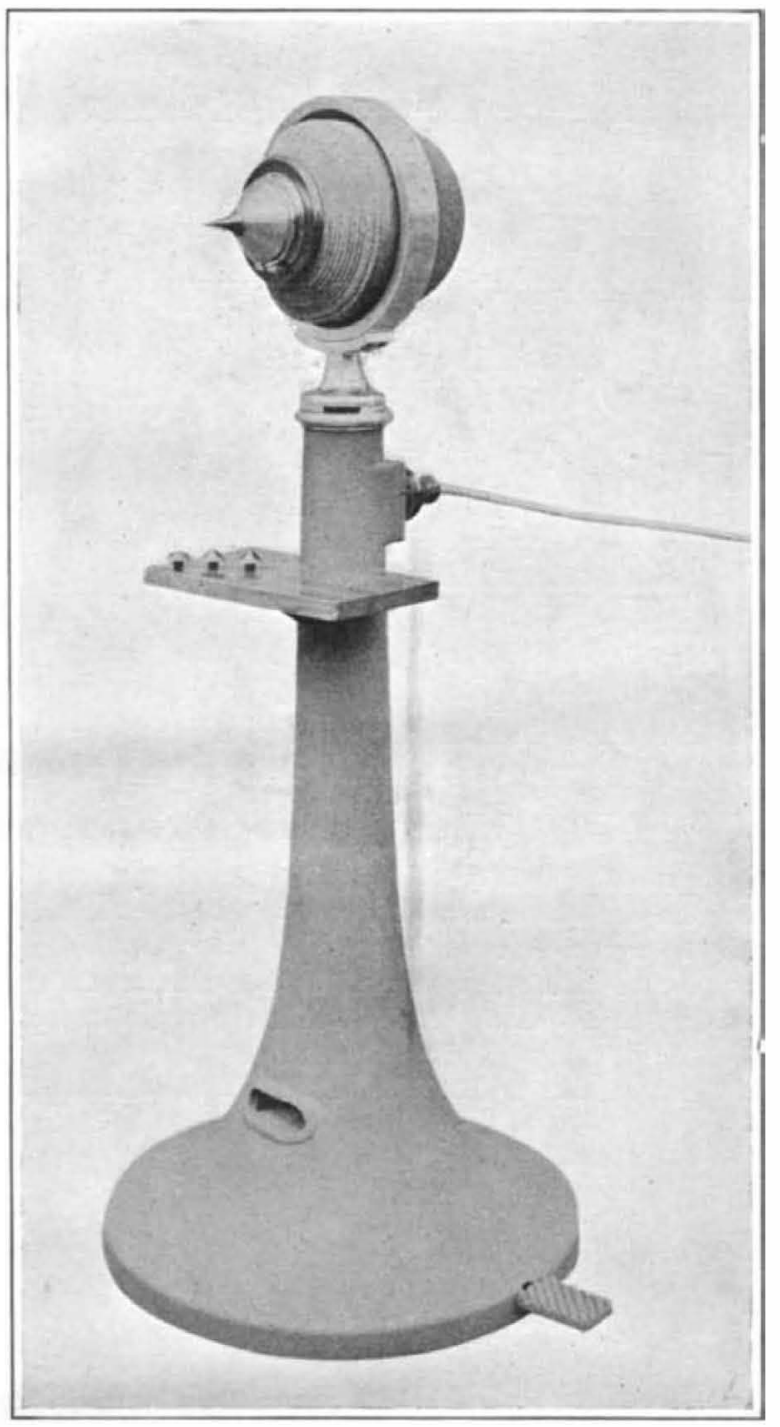

Foot-controlled electromagnet.
The magnet is mounted on a cast iron pillar, in such a manner that it can easily be turned in any direc tion. The pillar is hollow and is provided with castors, so that the apparatus can be moved without difficulty. The axis of the magnet is about four feet above the floor. At a little more than half this height a shelf is attached to the pillar for the purpose of supporting the patient's arms and keeping his head motionless during the operation.

The base of the pillar contains the electric switch which is closed by depressing a pedal and is thrown open by a spring the instant the foot is raised. A special device protects the contacts from injurious sparking. The current-density in the coil is very small in comparison with its density in other electromagnets. Hence very little heat is developed-a condition essen tial to permanent efficiency.

In tractive power Haab's electromagnet stands at the head of all known electromagnets used by oculists. At a distance of 1.2 inches, for example, it exerts a pull more than twice as strong as that of the largest Volkmann magnet.

The electromagnet is designed for use on direct current circuits of 60 to 300 volts, but it can be employed on alternating uniphase or triphase circuits, with the aid of a suitable transformer. The maximum power required is about one kilowatt. The total weight of the apparatus is about 286 pounds.

This apparatus, although designed primarily for the use of oculists, is admirably well adapted for the extraction of iron filings and splinters, hammer-scale, etc., from wounds in any part of the body. Hence it may advantageously be installed in the hospital rooms of all large mining and metallurgical establishments. Fxperience shows that the magnets now employed in these rooms are used as often on hands and arms as on eyes. Wounds incurred in planing iron are often filled with fine splinters of iron. The removal of these splinters singly with pincers or needles is a tedious and painful operation, but all of the iron or steel particles can be extracted quickly by means of a powerful magnet.

\section{A Seismograph in a Coal Mine}

NATURE states that a seismograph has recently been installed in the Tunnel Colliery, at Nuneaton, for the purpose of ascertaining whether the apparently inexplicable falls of coal and roof $i_{1}$ mines have any relation with the occurrence of earthquakes. Aside from the practical object in view, a comparison between the records of this instrument and those of in struments on the surface is likely to be of much scientific interest.

\section{Frost Fairs on the Thames}

ONDON winters are more remarkable for disma $\perp_{\text {drizzling rain and impenetrable fog than for snow }}$ and ice; but about half a dozen times in the last three hundred years truly arctic conditions have prevailed in that metropolis, and the River Thames has been frozen over so firmly that men and horses could go
upon it. Each of these periods has been the occasion upon it. Each of these periods has been the occasion of a "frost fair"; booths have been erected on the ice; printing presses set up, various sports and games indulged in; and the whole population has joined in celebrating the rare event.

The first great frost fair was held in January, 1608; but the most famous of all was that of 1683-4, which lasted from the beginning of December to the 5 th of February. Evelyn gives the following description of this fair in his "Diary": "The frost continuing more and more severe, the Thames before London was still planted with boothes in formal streetes, all sorts of plantes and shops furnish'd and full of commoditie trades and shops furnish'd and full of commodities, ven to a printing presse, where the people and ladyes tooke a fancy to have their names printed, and the day and yeare set down when printed on the Thames: this humour tooke so universally, that 'twas estimated the printer gain'd £5 a day, for printing a line onely, at sixpence a name, besides what he got by ballads, etc. Coaches plied from Westminster to the Temple, and from several other staires, to and fro, as in the streetes, sleds sliding on skeetes, a bull-baiting, horse and coach races, puppet-plays, and interludes, cookes, tipling, so that it seem'd to be a bacchanalian triumph, or carnival on the water." King Charles II. and his family visited the fair, and had their names printed on a quarto sheet of Dutch paper, which is still extant.
During the frost fair of January, 1716, it is recorded that an uncommonly high spring tide, which overflowed cellars on the banks of the river, raised th ice fully fourteen feet, without interrupting the people in their pursuits.

Similar fairs were held in $1740,1788-9$, and 1814 The last was one of the gayest and most animated of these events, though it lasted only four days.

\section{Meeting of the American Association}

THE sixty-third meeting of the American Association for the Advancement of Science will be held in Washington, December 27th to 30th, 1911, under the presidency of Prof. Charles E. Bessey, of the University of Nebraska. In conjunction therewith will be held the tenth of the "convocation week" meeting of affiliated societies, viz.: American Anthropological Association, Astronomical and Astrophysical Society of America, Society of American Bacteriologists, American Society of Biological Chemists, Botanical Societ of America, American Chemical Society, American Civic Alliance, American Economic Association, American Association of Economic Entomologists, Entomological Society of America, American Fern Society, American Folk-Lore Society, Association of American Geographers, Geological Society of America, American Federation of Teachers of the Mathematical and the Natural Sciences, American Home Economics Association, Society for Horticultural Science, American As sociation for Labor Legislation, American Microscopical Society, American Nature-Study Society, Paleontological Society of America, American Physical Society, American Physiological Society, American Phytonathological Society, American Psychological Association, Sigma Xi, American Sociological Association,
American Statistical Association, Sullivant Moss Society, Southern Society for Philosophy and Psychology. The administrative headquarters of the meeting will be at the New Willard Hotel, where all members will register, beginning at 9 o'clock, December 27th. The opening general session of the Association will be held at the U. S. National Museum at 8 P. M., December 27th. It is expected that an address of welcome will be given by the President of the United States, and the retiring president of the Association, Dr. A. A. Michaelson, will give his annual address, the subject being "Recent Progress in Spectroscopic Methods." The various sectional meetings begin at $10 \mathrm{~A}$. M., December 27th. The programme of entertainments in. cludes an exhibition cavalry drill at Ft. Myer, on the afternoon of December 28th, and an informal reception at the Corcoran Art Gallery the same evening.

\section{The Australian Antarctic Expedition}

D. MAWSON'S projected antarctic expedition has Decured a suitable vessel-the "Aurora," built at Dundee in 1876-and the preparations are proceeding rapidly. As we have previously stated, the object of this expedition is the thorough exploration of a portion of Antarctica, rather than a dash for the pole. It is announced that an aeroplane forms part of the equipment.

\section{The Scientific American-Gould Prize}

COPY of the rules governing the competition for A the flying machine prize of $\$ 15,000$ offered by $\mathrm{Mr}$. Edwin Gould under the auspices of the Scirntific AmErican will be found in the current issue of the Scientific American Supplemfnt. 